\title{
A Clinicopathological Study of Benign Lesions of the Vocal Fold
}

\author{
Dr. Partha Pratim Saha ${ }^{1}$, Dr. Sonali Jana ${ }^{2}$ \\ ${ }^{I}$ (RMO, Department Of ENT, Calcutta National Medical College, Kolkata, India) \\ ${ }^{2}(R M O$, Department Of ENT, Calcutta National Medical College, Kolkata, India)
}

\begin{abstract}
To find out the incidence of various types of benign mucosal lesions of the vocal fold causing hoarseness; To review the role of demographic, etiological and risk factors in relation to the benign mucosal lesions of the vocal fold. It was a Prospective, observational study. Patients with hoarseness, presenting the ENT and Head-Neck surgery department of a tertiary-care hospital from October 2014 to September 2015 were evaluated by indirect laryngoscopy, fibre-optic laryngoscopy and direct laryngoscopy followed by biopsy. Only those patients with benign vocal fold lesions, sixty in number, were selected. A clinical and epidemiologic profile was made from the data obtained from these patients. Vocal nodules were the commonest type of benign lesions of the vocal fold, followed by vocal fold polyps. Overall, there was a slight male predominance with maximum incidence in the age group 41-50 years. Risk factors for the development of such lesions were voice abuse and smoking more commonly. Dyspepsia, alcohol intake, fume exposure and allergy- these were other contributory factors for developing such lesions. These lesions were more common among low socio-economic class and urban population. Life-style modification (voice rest and voice rehabilitation, cessation of smoking, avoidance of alcohol and spicy food) plays a vital role to reduce the incidence of these benign vocal fold lesions significantly.
\end{abstract}

Keywords: Benign Vocal fold Lesions, Fibre-optic laryngoscopy, Hoarseness, vocal nodule, vocal fold polyp.

\section{Introduction}

The voice is the primary means of communication for humans. An alteration in the voice is called hoarseness. More specifically, hoarseness is defined as an altered vocal quality, pitch, loudness, or vocal effort that impairs communication or reduces voice-related quality of life ${ }^{[1]}$.

Although hoarseness has an ICD-9 code, it is not a disease; it is a symptom of a disease. Any patient with hoarseness of two weeks duration or longer must undergo visualization of the entire larynx , specifically the vocal folds as the main causes for the hoarseness are mostly related to the mass, margin and movement of the vocal folds. There are a variety of benign mucosal lesions of the vocal fold that result in hoarseness. Some of the more common lesions are vocal fold polyps, nodules, cysts, granulomas, polypoid corditis (Reinke's edema), glottic sulcus and papillomatosis.

Benign vocal fold mucosal lesions seem to be caused primarily by vibratory trauma. Occupational and lifestyle vocal demands are the primary risk factors along with excessive talkativeness. Cigarette smoking, acid reflux, allergy, infection also may increase the vulnerability of vocal fold mucosa to vibratory trauma, leading to injury. Non-singers with benign vocal fold mucosal disorders present with a change in sound or capabilities of a speaking voice. Singers with normal speaking voices may seek professional evaluation because of singing voice limitations, usually in the upper range.

More than $50 \%$ of patients with voice complaints have benign vocal fold disorders. Brodnitz ${ }^{[2]}$ reported $45 \%$ of 977 patients had a diagnosis of nodules, polyps or polypoidal thickening. Kleinsasser ${ }^{[3]}$ (1964-1975) reported that slightly more than $50 \%$ of 2618 patients had one of these benign entities.

Our study will focus on the benign mucosal lesions of the vocal fold which causes hoarseness and which are very frequent in our hospital set up. The aims of our study are:

a) To find out the incidence of various types of benign mucosal lesions of the vocal fold causing hoarseness.

b) To review the role of demographic, etiological and risk factors in relation to the benign mucosal lesions of the vocal fold.

\section{Materials And Methods}

The study was undertaken in the department of E.N.T and Head-Neck Surgery of a tertiary care hospital in Kolkata, over a period of one year (October 2014 to September 2015).The study design was a prospective observational one.

2.1 Inclusion Criteria: All patients with lesions in the mucosal layer of the vocal fold whose histopathological examinations are eventually proved to be benign. 


\subsection{Exclusion Criteria:}

a) All patients with lesions in the mucosal layer of the vocal fold whose histopathological examinations are eventually proved to be malignant.

b) Patients with vocal fold palsy.

c) Patients with acute vocal fold infections.

The study was approved by the Institutional Review Board. 60 patients were selected as per the inclusion and exclusion criteria. Informed, written consents were obtained from all individual participants included in the study. Detailed history was noted in a customized proforma. Demographic data (Name, Age, Sex, Address, Occupation, Socio-economic status) are properly collected from each patient during history taking. Profession, habit of smoking and alcohol intake, allergy, hyperacidity- these informations were specifically enquired to predict any possible risk factors. Any medical condition relating to the patient like diabetes, hypertension and hypothyroidism were noted.

Thorough physical examination of each patient was done in the outpatient department. Indirect laryngoscopy was performed in all the cases to diagnose vocal fold pathology. These patients were then posted for Fibre optic laryngoscopy where detailed study of their vocal fold pathology was done with the help of $70^{\circ}$ laryngoscopes. Then microlaryngeal surgery was planned and performed under general anaesthesia followed by histopathological examination of lesions of excised tissue to confirm its benign pathology.

\section{Results}

The total number of patients having benign mucosal lesions of the vocal folds included in this study was 60 . Out of them, $36(60 \%)$ had vocal fold nodules, 12 (20\%) had polyp, 3 presented with intracordal cyst, 2 had reinke's oedema, 2 had contact ulcer, 1 had intubation granuloma, 3 presented with glottis sulcus, and rest 1 had papilloma (Table 1).

Table 1: Total case distribution among patients having benign vocal fold lesions

\begin{tabular}{|c|c|c|c|c|c|c|c|c|}
\hline & Nodule & Polyp & $\begin{array}{c}\text { Intracordal } \\
\text { cyst }\end{array}$ & $\begin{array}{c}\text { Reinke's } \\
\text { oedema }\end{array}$ & $\begin{array}{c}\text { Contact } \\
\text { ulcer }\end{array}$ & $\begin{array}{c}\text { Intubation } \\
\text { granuloma }\end{array}$ & $\begin{array}{c}\text { Glottic } \\
\text { sulcus }\end{array}$ & Papilloma \\
\hline $\begin{array}{c}\text { Number } \\
\text { of cases }\end{array}$ & 36 & 12 & 3 & 2 & 2 & 1 & 3 & 1 \\
\hline
\end{tabular}

There were 32 males and 28 females in the present study with a male: female ratio of 8:7. The overall sex distribution showed a female preponderance over male in cases of nodules, equal in cases of Reinke's oedema and the rest had a male preponderance (Table 2).

Table 2: Sex distribution among patients having benign vocal fold lesions

\begin{tabular}{|l|l|l|l|l|l|l|l|l|}
\hline & Nodule & Polyp & Intracordal cyst & $\begin{array}{l}\text { Reinke's } \\
\text { oedema }\end{array}$ & $\begin{array}{l}\text { Contact } \\
\text { ulcer }\end{array}$ & $\begin{array}{l}\text { Intubation } \\
\text { granuloma }\end{array}$ & $\begin{array}{l}\text { Glottic } \\
\text { sulcus }\end{array}$ & Papilloma \\
\hline Male & 15 & 8 & 2 & 1 & 2 & 1 & 2 & 1 \\
\hline Female & 21 & 4 & 1 & 1 & 0 & 0 & 1 & 0 \\
\hline
\end{tabular}

In our study the maximum incidence of benign lesions were found in the age group of $41-50$ years. The mean age of the patients was 42.25 years, ranging from 12 to 75 years. Hoarseness, in our study was one of the most prominent presenting symptoms and was present invariably in all the cases (100\%) that were being reported. Fatigueness of voice was the second most common presenting symptom (80\%) followed by foreign body sensation (50\%), heart burn( $2 \%$ ) and dry cough (1\%) (Table 3$)$.

Table 3: predominant symptoms of patients.

\begin{tabular}{|l|l|l|}
\hline Predominant symptoms & No. of patients & Percentage \\
\hline Hoarseness & 60 & $100 \%$ \\
\hline Vocal fatigue & 48 & $80 \%$ \\
\hline Foreign body sensation & 30 & $50 \%$ \\
\hline Heart burn & 2 & $3 \%$ \\
\hline Dry cough & 1 & $1 \%$ \\
\hline
\end{tabular}

We studied the role of occupation for causing benign vocal fold lesions. We found that, out of 60 cases, 18 were housewives, 10 were office workers, 9 were hawkers, another 9 were teachers, 6 were singers and rest 8 were students. Among all of them, majority presented with either vocal cord nodule or polyp (Table 4). 
Table 4: Occupation wise distribution of the patient

\begin{tabular}{|l|l|l|}
\hline Occupation & No. of cases & Percentage \\
\hline House wives & 18 & $30 \%$ \\
\hline Office workers & 10 & $16.6 \%$ \\
\hline Hawkers & 9 & $15 \%$ \\
\hline Singers & 6 & $10 \%$ \\
\hline Teachers & 9 & $15 \%$ \\
\hline Students & 8 & $13.3 \%$ \\
\hline
\end{tabular}

From our study it can be seen that patients belonging to the low class societies had the incidence of benign vocal fold lesions much more (46\%) than middle $(30 \%)$ and high class $(23 \%)$. We found that patients from urban areas were having comparatively higher $(58 \%)$ vocal cord lesions than patients from rural areas $(43 \%)$. Out of 60 patients having benign vocal fold lesions, $30(50 \%)$ were chronic smokers. Dyspepsia is seen in 20 patients $(33 \%)$ with vocal cord nodules, vocal cord polyps followed by contact ulcer. 15 patients $(25 \%)$ out of 60 were alcoholics among them 12 had been diagnosed with nodules, 1 each with polyp, contact ulcer and papilloma. 12 cases $(20 \%)$ had a history of exposure to fumes. Allergic association is seen in 8 cases having mostly polyps and nodules followed by intracordal cysts and contact ulcer (Table 5).

Table 5: Association of risk factors in benign vocal fold lesions

\begin{tabular}{|l|l|l|}
\hline Risk factors & No. of Patients & Percentage \\
\hline Smoking & 30 & $50 \%$ \\
\hline Dyspepsia & 20 & $33 \%$ \\
\hline Alcoholics & 15 & $25 \%$ \\
\hline Fume exposure & 12 & $20 \%$ \\
\hline Allergy & 8 & $16 \%$ \\
\hline
\end{tabular}

\section{Discussion}

In our study, out of the 60 vocal fold lesions, the largest subset comprised of nodules (60\%). The second most common pathology in the present study was vocal fold polyps (20\%). Siddapur GK et al ${ }^{[4]}$ also found that vocal nodules are the most common benign vocal fold lesions but with lower incidence rate of $35 \%$ observed in their study. Mahesh Chandra et al ${ }^{[5]}$ reported an incidence of $28.57 \%$ and $24 \%$, on vocal nodules and vocal polyps respectively. Kotby et al ${ }^{[6]}$ reported similar results. In studies by Kambic et al ${ }^{[7]}$ and Chopra et al ${ }^{[8]}$ the incidence varied from 68.3 to $16 \%$. We observed that maximum incidence of benign lesions were in the age group of 41 - 50 years which is considered important period of life. This finding is similar to the result of Chinthapeta K K et al ${ }^{[9]}$. On the other hand, Hegde MC et al ${ }^{[10]}$ and Singhal P et al ${ }^{[11]}$ in their study reported maximum number of the patient in the age group of 20 to 40 years.

In our study $53 \%$ of cases were males when compared to females, which was supported by Stewart JP et al ${ }^{[12]}$, Chopra et al ${ }^{[13]}$, Batra et al ${ }^{[14]}$ and Chinthapeta $\mathrm{K} \mathrm{K}$ et al ${ }^{[9]}$. All of them showed male preponderance in their publications. In the present study, hoarseness, vocal fatigue and foreign body sensation were the commonest presenting symptoms having $100 \%, 80 \%$ and $50 \%$ respectively. This observation is quite similar to the findings by Siddapur GK et al ${ }^{[4]}$.Singhal $\mathrm{P}$ et al ${ }^{[11]}$ noticed that benign lesions of the vocal folds found most commonly among imams of mosque and temple singers. Chinthapeta K K et al ${ }^{[9]}$ in their study observed that teaching profession appeared to be the common occupational group having the benign lesions of the vocal cord. In our study, housewives were the largest group (30\%) having vocal cord lesions.

From our study it can be seen that patients belonging to the low class societies had the incidence of benign vocal fold lesions much more (46\%) than middle $(30 \%)$ and high class $(23 \%)$. We found that patients from urban areas were having comparatively higher $(58 \%)$ vocal cord lesions than patients from rural areas $(43 \%)$. Elwood et al $^{[15]}$; Hirayama ${ }^{[16]}$ and Menvielle et al ${ }^{[17]}$ agreed that low social class found to be a significant risk factor for a subject to be a patient with chronic voice disorder. Lastly, in the study by A. El-Moselhy et al ${ }^{[18]}$ urban residence found to be a significant risk factor for chronic voice disorders.

Regarding smoking, it is a risk factor for voice disorders. Cigarette smoke is chronically irritating to the laryngeal mucosa and at the extreme it can provoke cancer (Hanson and Jiang, 2000) ${ }^{[19]}$. We showed that $50 \%$ of the patients with chronic voice disorders were smokers. This result is consistent with Kambic et al ${ }^{[20]}$. Also, Garcia et al ${ }^{[21]}$ found that smoking was the main risk factor for vocal folds polyps and edema, which will lead to dysphonia. Alcohol intake represented a risk factor for voice disorders in $25 \%$ of the patients. This result was consistent with Rothman et al ${ }^{[22]}$, Guenel et al ${ }^{[23]}$ and Altieri et al ${ }^{[24]}$.

\section{Conclusion}

We conclude that the most common causes of benign vocal fold lesion causing hoarseness are vocal nodules followed by vocal fold polyps. The 41-50 year age group, low social class, urban residence and male gender are the most important socio-demographic risk factors of chronic voice disorders. At the same time, the 
results of the study confirmed that patients with the habit of voice abuse, smoking, alcohol intake as well as dyspepsia, allergy, and fume exposure are clinically more prone to chronic voice disorders.

The present study emphasizes that it is not only the surgery that is important in managing vocal fold lesions, but also the life-style modification (voice rest and voice rehabilitation, cessation of smoking, avoidance of alcohol and spicy food, and going to sleep not less than two hours after food) that plays a vital role to reduce the incidence of these benign vocal fold lesions significantly.

So, it is recommended to focus research efforts, health education and clinical practices on the chronic voice disorders. More work should be conducted in more areas to determine the epidemiology of the patients with chronic voice disorders in India.

\section{References}

[1]. Schwartz SR et al. Clinical practice guideline: hoarseness (dysphonia). Otolaryngol Head neck surg. 2009 Sep;141(3 Suppl 2):S1S31.

[2]. Brodnitz FS. Results and limitation of vocal rehabilitation. Arch Otolaryngol Head Neck Surg. 1963;77:148.

[3]. Kleinsasser O. Microlaryngoscopy and endolaryngeal microsurgery: technique and typical findings, ed 2, (Baltimore, University Park Press, 1979)

[4]. Mahesh C, Panduranga KM, Kiran B, Ranjith P, Ravi BP. Benign lesions of larynx-a clinical study. Indian J Otolaryngol Head Neck Surg. 2012; 57:35-8.

[5]. Kotby MN, Nassar AM, Seif EI, Helal EH, Saleh MM. Ultrastructural features of vocal fold nodules and polyps. Acta Otolaryngol. $1988 ; 105: 477-82$.

[6]. Kambic V, Radsel Z, Zarqi M, Acko M. Vocal cord polyps: incidence, histology and pathogenesis. J Laryngol Otol. 1981; 95:60918.

[7]. Chopra H, Kapoor M. Study of benign glottic lesions undergoing microlaryngeal surgery. Indian J Otolaryngol Head Neck Surg. 1997; 49:276-9.

[8]. Siddapur GK et al. Comparative study of benign vocal fold lesions in a tertiary health centre. Int J Otorhinolaryngol Head Neck Surg. 2015 Oct; 1(2):65-68.

[9]. Hegde MC, Kamath PM, Bhojwani K, Peter R, Babu PR. Benign lesions of the larynx: A clinical study. IJLO. 2005; 57(1):35-38.

[10]. Singhal P, Bhandari A, Chouhan M, Sharma MP, Sharma S. Benign tumors of the larynx: A clinical study of 50 cases. IJLO. 2009 ; 61(1):26- 30 .

[11]. Stewart JP. The histopathology of benign tumors of the larynx. J Laryngol Otol. 1957; 71:718-29.

[12]. Chopra H, Kapoor M; Study of benign glottic lesions undergoing micro laryngeal surgery. Indian Journal of Otolaryngology and Head and Neck Surgery. 1997; 49(3):276-79.

[13]. Batra K, Motwani Ani G, Sagar PC; Functional voice disorders and their occurrence in 100 patients of hoarseness as seen in oil fibreoptic laryngoscopy. Indian J Otolaryngol Head and Neck Surgery. 2004; 56(21):91-95.

[14]. Kiran Kumar Chinthapeta, M.K. Srinivasan, K Muthu Babu, Asim Pa , G. Jeeva , C. Sampath. Prevalence of Benign Lesions of Vocal Cord in Patients with Hoarseness - A Cross Sectional Study. Scholars Journal of Applied Medical Sciences. 2015; 3(7B):2518-2521.

[15]. Elwood IM, Sakamoto T, Barnes PJ and Chung KF (1984): Alcohol, smoking, social and occupational factors in the etiology of cancer of the oral cavity, pharynx and larynx. Intl Cancer. 34: 603-7.

[16]. Hirayama T. Life-style and morta-lity: A large-scale census-based cohort study in Japan. In: Contributions to epidemiology and biostatistics, Wahrendorf J (Ed), Basel, Karger, 1990.

[17]. Menvielle G, Luce D, Goldberg P and Leclerc A. Smoking, alcohol drinking, occupational exposures and social inequalities in hypopharyngeal and laryngeal cancer. Int J Epidemiol. 2004; 11: 20-5.

[18]. E. A. El-Moselhy et al. Risk Factors And Quality Of Life Of Adult Patients With Chronic Voice Disorders .The Egyptian Journal of Hospital Medicine. 2008; Vol., 30: 90-103.

[19]. Hanson DG and Jiang JJ. Diagnosis and management of chronic laryngitis associated with reflux. Am J Med. 2000; 108 (S 4a): 1125-9.

[20]. Kambic V, Radsel Z, Zargi M and Acko M. Vocal cord polyps: Incidence, histology, and pathogenesis. J Laryngol Otol. 1981; 95(6): 609-18.

[21]. Garcia Alvarez CD, Campos Banales ME, Lopez Campos D, Rivero J, Perez Pinero B and Lopez Aguado D (1999): Polyps, nodules, and Reinke's edema: An epidemiological and histopathological study. Acta Otorrinolaringol Esp, 50(6): $443-7$.

[22]. Rothman KJ, Cann CI, Flanders D and Fried MP. Epidemiology of laryngeal cancer. Epidemiology. 1980; 2: $195-209$.

[23]. Guenel P, Chastang JF, Luce D, Leclerc A and Brugere J. A study of the interaction of alcohol drinking and tobacco smoking among French cases of laryngeal cancer. J Epidemiol Comm Health. 1988; 42 (4): 350-4.

[24]. Altieri A et al. Cessation of smoking and drinking and the risk of laryngeal cancer. Br J Cancer. 2002; 18(11): 1227-9. 